\title{
ATIVIDADE ANTIBACTERIANA "IN VITRO" DE DIFERENTES ACESSOS DE URUCUM (Bixa orellana L.) E SUA RELAÇÂO COM O TEOR DE BIXINA PRESENTE NAS SEMENTES
}

\author{
CLÁUDIA MAJOLO* \\ HELOISA HELENA CARVALHO * \\ JOSÉ MARIA WIEST ${ }^{* * *}$
}

\begin{abstract}
Determinou-se a intensidade de atividade de inibição bacteriana (IINIB/bacteriostasia) e a intensidade de atividade de inativação bacteriana (IINAB/bactericidia) de soluções contendo extratos hidroetanólico e hídricos (decocto e infuso) de três acessos de Bixa orellana L. (Arroio do Meio/RS, Eldorado do Sul/RS e Maringá/ PR) sobre inóculos padronizados de Salmonella enteritidis (ATCC 11076), Escherichia coli (ATCC 11229), Staphylococcus aureus (ATCC 25923), Enterococcus faecalis (ATCC 19433) e Listeria monocytogenes (ATCC 19114). Determinou-se paralelamente o teor de bixina nas sementes. Os extratos hídricos apresentaram baixa atividade de inibição e/ou inativação sobre os inóculos bacterianos, enquanto a forma de extração hidroetanólica revelou atividade antibacteriana seletiva e significativamente mais intensa (inibição/ inativação) entre as cinco bactérias testadas. Independente da forma de extração, as bactérias $E$. faecalis e L. monocytogenes foram as mais sensíveis à atividade antibacteriana, enquanto E. coli apresentou a menor sensibilidade. Verificou-se diferença significativa entre os teores de bixina entre os três acessos, e, consequentemente, a atividade antibacteriana determinada mostrouse diretamente proporcional a esses teores.
\end{abstract}

PALAVRAS-CHAVE: Bixa orellana; ATIVIDADE ANTIBACTERIANA; INIBIÇÃO BACTERIANA; INATIVAÇÃO BACTERIANA; BIXINA.

* $\quad$ Mestre em Ciência e Tecnologia de Alimentos pela Universidade Federal do Rio Grande do Sul (UFRGS), analista, EMPRAPA Amazônia Ocidental, Manaus, AM (e-mail: claudia.majolo@embrapa.br).

** Doutora em Ciências Veterinárias, funcionária, UFRGS, Porto Alegre, RS (e-mail: hhcarvalho@terra. com.br)

*** Doutor em Medicina Veterinária, professor, UFRGS, Porto Alegre, RS (e-mail:00002497@ufrgs.br). 


\section{INTRODUÇÃO}

Uma das maiores preocupações para evitar a contaminação microbiana por parte da indústria de alimentos envolve o uso de preservantes químicos, que podem ser substituídos por alternativas naturais menos prejudiciais à saúde e mais viáveis economicamente (VIUDA-MARTOS et al., 2008).

Pesquisas relacionadas à atividade antimicrobiana de compostos naturais sobre a multiplicação bacteriana podem levar a sua utilização em novas tecnologias, melhorando a qualidade e a segurança alimentar (MAU et al., 2001).

O uso indiscriminado de drogas antimicrobianas tornou crescente o problema da resistência bacteriana, exigindo o controle do emprego dessas drogas e a pesquisa de novos antimicrobianos, tanto sintéticos como naturais ou a associação de ambos (NASCIMENTO et al., 2000).

Numerosas manifestações, conforme relatado por Livermore (2007), demonstram e justificam a necessidade de diminuir o uso de antimicrobianos em geral e de aplicá-los da forma mais correta possível, adotando-se medidas profiláticas cada vez mais eficazes.

Bixa orellana L. (urucum), árvore pequena, é originária da América tropical, incluindo a Amazônia brasileira. Alcança no máximo cinco metros de altura e apresenta copa bem desenvolvida. Suas folhas são simples, glabras, medindo de 8 a 11 centímetros de comprimento. As flores são levemente rosas e o fruto (cápsula deiscente ovoide) contém dois a três carpelos, cobertos por espinhos. O óleo essencial das sementes é rico em all-E-geranilgeraniol, monoterpenos e sesquiterpenos oxigenados, além dos carotenoides bixina e norbixina (contendo em menor quantidade alfa e beta-caroteno). $\mathrm{O}$ uso de óleo na medicina popular ocorre principalmente para doenças coronarianas, afecções do estômago e intestino, afecções respiratórias, queimaduras, e como afrodisíaco (LORENZI E MATOS, 2008).

$O$ uso de $B$. orellana $L$. (urucum) vem ganhando espaço cada vez mais pronunciado em diversos setores industriais, principalmente na área de laticínios. A substituição de corantes sintéticos por urucum se deve à sua baixa toxicidade e baixo custo de produção, tornando-o muito conveniente e atrativo (AGNER et al., 2004).

B. orellana L. (urucum) tem sido utilizado pela Comunidade Europeia e nos Estados Unidos da América (EUA) como corante natural em diversos alimentos (sorvetes, queijos, manteigas e peixes defumados) (DOWNHAM \& COLLINS, 2000). No Brasil, foi classificado como aditivo alimentar (corante), ou seja, substância que confere, intensifica ou restaura a cor de determinado alimento (BRASIL, 1997).

Estudos com urucum mostraram sua atividade antimicrobiana e sua capacidade de conservação e agregação de qualidade aos alimentos (BRAGA et al., 2007; ROJAS et al., 2006; GONÇALVES, 2005; NALIMOVA et al., 2005; FLEISCHER et al., 2003; IROBI et al., 1996). GalindoCuspinera \& Rankin (2005) demonstraram que as frações à base de norbixina são responsáveis pela atividade antibacteriana do urucum, principalmente frente à $S$. aureus.

Este trabalho teve como objetivo avaliar a atividade bacteriostática/inibição e bactericida/ inativação "in vitro" de extratos hidroetanólicos e hídricos (decoctos e infusos), obtidos de diferentes acessos de sementes de $B$. orellana $L$. (urucum) originários dos municípios de Arroio do Meio (RS), Eldorado do Sul (RS) e Maringá (PR) frente a agentes bacterianos padrões internacionais de interesse em alimentos, respectivamente Salmonella Enteritidis, Escherichia coli, Staphylococcus aureus, Enterococcus faecalis e Listeria monocytogenes. Além disso, foram avaliadas as atividades antibacterianas com a presença ou ausência de desinibidores bacterianos, bem como o teor de bixina presente nas sementes, permanecendo constante $(50 \%)$ a concentração final de uso dos diferentes extratos nas denominadas soluções conservantes.

\section{MATERIAL E MÉTODOS}

As sementes de Bixa orellana L. (urucum) foram acessadas em propriedade agroecológica 
familiar no Parque Eldorado, município de Eldorado do Sul/RS (coordenadas $30^{\circ} 05^{\prime} \mathrm{S}$ e $51^{\circ} 40^{\prime} \mathrm{W}$ ), em propriedade familiar no município de Arroio do Meio/RS (coordenadas $29^{\circ} 24^{\prime} \mathrm{S}$ e $51^{\circ} 56^{\prime} \mathrm{W}$ ) e em propriedade agrícola no município de Maringá/PR (coordenadas $23^{\circ} 25^{\prime} \mathrm{S}$ e $51^{\circ} 56^{\prime} \mathrm{W}$ ). Esses acessos foram selecionados devido à facilidade de coleta e de sua relação com o conhecimento popular local, relacionando os usos condimentares e medicinais (Arroio do Meio e Parque Eldorado) e de exploração agrícola (Maringá).

O material foi herborizado segundo Ming (1996) e catalogado pela bióloga Sílvia Marodin (CRBio/ RS n ${ }^{\circ}$ 17268), sendo a duplicata botânica incorporada ao Herbário do Departamento de Botânica, Instituto de Biociência, da Universidade Federal do Rio Grande do Sul (UFRGS) sob os seguintes números de registro: 189642 (acesso Maringá/PR), 189643 (acesso Arroio do Meio/RS), 189644 (acesso Eldorado do Sul/RS).

As sementes de $B$. orellana L. (urucum), previamente secas, sob controle de temperatura e reidratação foram submetidas aos processos de extração hidroetanólica e hídrica (decocção e infusão) para obtenção dos extratos (FARMACOPÉIA..., 1987; ITF, 2008; LIMA, 2008; LORENZI e MATOS, 2008). O extrato hidroetanólico foi elaborado a partir das sementes, colocadas em etanol de cereais (Farmaquímica, Porto Alegre/RS), a $70^{\circ} \mathrm{GL}$, na proporção de $100 \mathrm{~g}$ de sementes para $1000 \mathrm{~mL}$ de álcool. Após quinze dias, o extrato foi submetido à destilação fracionada sob pressão reduzida em sistema rota vapor (FISATON ${ }^{\circledR}$ ), desprezando-se a porção alcoólica e reidratando-se o extrato resultante com água destilada estéril para reconstituir as concentrações iniciais da planta. Preparou-se o decocto na proporção de $100 \mathrm{~g}$ de semente para $1000 \mathrm{~mL}$ de água destilada estéril, mantido sob ebulição durante 20 minutos em aquecedor com refluxo e repondo-se assepticamente o volume inicial. Para o infuso empregou-se a proporção de $100 \mathrm{~g}$ de semente para $1000 \mathrm{~mL}$ de água destilada estéril em ebulição, depositada sobre as sementes pelo período de 20 minutos. Para o controle permanente da assepsia dos procedimentos de extração e reconstituição determinou-se a esterilidade de todos os extratos (PASSOS, CARVALHO e WIEST, 2009). Alíquotas de $5 \mathrm{~mL}$ dos extratos foram semeadas em tubos contendo $5 \mathrm{~mL}$ de Caldo-Cérebro-Coração (BHI, HIMEDIA, Mumbai/Índia), incubados aeróbicamente a $37^{\circ} \mathrm{C}$ por até 48 horas. Confirmou-se sua esterilidade por plaqueamento em Ágar Nutriente (Nutrient Agar, ACUMEDIA, Maryland/Baltimore/USA).

Para o confronto entre os extratos e agentes bacterianos de interesse em alimentos foram utilizadas amostras de inóculos padrões American Type Culture Colletion (ATCC), visando à avaliação da atividade antibacteriana (IINIB/bacteriostasia e IINAB/bactericidia) dos diferentes extratos de sementes para Salmonella Enteritidis (ATCC 11076), Escherichia coli (ATCC 11229), Staphylococcus aureus (ATCC 25923), Enterococcus faecalis (ATCC 19433) e Listeria monocytogenes (ATCC 19114), provenientes da coleção-bacterioteca do Laboratório de Higiene de Alimentos do Instituto de Ciência e Tecnologia de Alimentos (ICTA) da UFRGS. Os inóculos foram reativados em meio de cultura $\mathrm{BHI}$ a $37^{\circ} \mathrm{C}$ durante 18 a 24 horas de incubação aeróbia, com o objetivo de atingir concentração $\geq 1,0 \times 10^{8} \mathrm{UFC} / \mathrm{mL}$ para confrontação com os diferentes extratos de sementes de $B$. orellana L. (urucum), mediante diluições seriais logarítmicas (SOUZA e WIEST, 2007; AVANCINI e WIEST, 2008; CARVALHO, WIEST e CRUZ, 2010). Avaliou-se a concentração inicial pela técnica da microgota, conforme Romeiro (2007), sendo a contagem de micro-organismos viáveis concretizada em placas de Petri contendo meio de cultura PCA (Plate Count Agar, HIMEDIA, Mumbai/Índia). Foram realizadas diluições seriadas, a partir do inóculo inicial, transferindo-se $1 \mathrm{~mL}$ desse para tubos de ensaio contendo $9 \mathrm{~mL}$ de água peptonada 0,1\% (BIOBRÁS, Montes Claros/ Brasil) para se obter a diluição $10^{-1}$, e assim sucessivamente até a diluição $10^{-12}$. De cada diluição foram transferidas, isoladamente, três gotas (alíquotas contendo $15 \mu \mathrm{L}$ cada) para placas de Petri, utilizando-se micropipetas, sendo a leitura realizada após 24 horas de incubação aeróbia a $37^{\circ} \mathrm{C}$. O valor final considerado representou a média das contagens das gotas triplicadas, avaliadas biometricamente segundo Cavalli-Sforza (1974).

Para a determinação da atividade antibacteriana dos extratos de sementes de $B$. orellana L. (urucum), lida como Intensidade de Atividade de Inibição Bacteriana/bacteriostasia 
(IINIB) e Intensidade de Atividade de Inativação Bacteriana/bactericidia (IINAB), utilizou-se o teste de diluição segundo a Deutsche Veterinärmedizinische Gesellschaft/Sociedade Alemã de Medicina Veterinária (DVG, 1980), com base na Técnica do Sistema de Tubos Múltiplos. Essa técnica, também utilizada por Souza \& Wiest (2007), Avancini e Wiest (2008), Avancini et al. (2008), Wiest et al. (2009) e Carvalho, Wiest e Cruz (2010), baseia-se no confronto dos diferentes extratos com 12 diluições seriais logarítmicas $\left(10^{-1}\right.$ a $\left.10^{-12} \mathrm{UFC} / \mathrm{mL}\right)$ dos diferentes inóculos bacterianos.

Entende-se por IINIB/bacteriostasia, o resultado do confronto da bactéria com a solução antibacteriana em meio específico e por IINAB/bactericidia, o mesmo resultado sob a influência dos desinibidores ou desestressantes bacterianos acrescidos ao BHI (AVANCINI et al., 2008; AVANCINI e WIEST, 2008; WU, 2008; WIEST et al., 2009; CARVALHO, WIEST e CRUZ, 2010). Esses valores são representações da atividade biológica inibitória/bacteriostasia ou inativadora/bactericidia de diferentes soluções antibacterianas sobre os micro-organismos.

Os resultados da intensidade da atividade de inibição bacteriana/bacteriostasia (IINIB) e da intensidade da atividade de inativação bacteriana/bactericidia (IINAB) foram representados por variáveis ordinais arbitrárias, que assumiram valores de 12 a 0 . O valor 12 (doze) representa a atividade máxima e o 0 (zero) significa não atividade conforme demonstrado no Quadro 1.

\section{QUADRO 1 - REPRESENTAÇÃO DOS VALORES ORDINAIS ARBITRÁRIOS DE INTENSIDADE ATRIBUÍDOS ÀS VARIÁVEIS INTENSIDADE DA ATIVIDADE DE INIBIÇÃO BACTERIANAI BACTERIOSTASIA (IINIB) E INTENSIDADE DA ATIVIDADE DE INATIVAÇÃO BACTERIANA/BACTERICIDIA (IINAB) E SUAS CORRESPONDENTES DILUIÇÕES E DOSES INFECTANTES DOS INÓCULOS}

\begin{tabular}{|c|c|c|c|c|c|c|c|c|c|c|c|c|l|}
\hline 12 & $\mathbf{1 1}$ & $\mathbf{1 0}$ & $\mathbf{9}$ & $\mathbf{8}$ & $\mathbf{7}$ & $\mathbf{6}$ & $\mathbf{5}$ & $\mathbf{4}$ & $\mathbf{3}$ & $\mathbf{2}$ & $\mathbf{1}$ & $\mathbf{0}$ & $\begin{array}{l}\text { Variáveis ordinárias de } \\
\text { intensidade de atividade }\end{array}$ \\
\hline $10^{-1}$ & $10^{-2}$ & $10^{-3}$ & $10^{-4}$ & $10^{-5}$ & $10^{-6}$ & $10^{-7}$ & $10^{-8}$ & $10^{-9}$ & $10^{-10}$ & $10^{-11}$ & $\begin{array}{c}10^{-} \\
12\end{array}$ & n.a & $\begin{array}{l}\text { UFC/mL - diluições de inoculo } \\
\text { inibidas ou inativadas }\end{array}$ \\
\hline $10^{7}$ & $10^{6}$ & $10^{5}$ & $10^{4}$ & $10^{3}$ & $10^{2}$ & $10^{1}$ & 1 & $10^{-1}$ & $10^{-2}$ & $10^{-3}$ & $10^{-4}$ & n.a & $\begin{array}{l}\text { UFC/mL - doses infectantes } \\
\text { inibidas ou inativadas }\end{array}$ \\
\hline
\end{tabular}

n.a = ausênsia de atividade antibacteriana; UFC $/ \mathrm{mL}=$ unidades formadoras de colônias por $\mathrm{mL}$.

Os resultados da avaliação da atividade antibacteriana (IINIB e IINAB) das diferentes soluções conservantes extraídas de $B$. orellana $L$. (urucum) foram tratados por meio do programa de análises estatísticas SISVAR 5.0 (2009), mediante Análise de Variância (Anova) e teste de Tukey.

Para a determinação do teor de bixina nas sementes de $B$. orellana L. (urucum) utilizou-se o método $\mathrm{KOH}$, citado por Veríssimo et al. (2008). Foram pesadas $50 \mathrm{~g}$ de sementes em Erlenmeyer de $500 \mathrm{~mL}$ e adicionados $150 \mathrm{~mL}$ de solução $\mathrm{KOH} 5 \% \mathrm{P} / \mathrm{V}$, sendo a mistura levada à ebulição e mantida nesse estado por 1 minuto. A mistura foi resfriada sem agitação em água corrente e, posteriormente, filtrada em funil de vidro/lã de vidro. As sementes foram lavadas com água destilada $(100 \mathrm{~mL})$ por sete vezes, o volume do balão volumétrico foi completado até $1000 \mathrm{~mL}$ e seu conteúdo homogeneizado por inversão. Transferiu-se uma alíquota de $2 \mathrm{~mL}$ dessa solução para balão volumétrico de $1000 \mathrm{~mL}$, completou-se o volume com solução de $\mathrm{KOH} \mathrm{0,5 \%} \mathrm{P/V} \mathrm{e} \mathrm{procedeu-se} \mathrm{a}$ homogeneização por inversão. Efetuou-se a leitura da absorbância da solução em espectrofotômetro a $453 \mathrm{~nm}$, em célula de $1 \mathrm{~cm}$ de percurso óptico, contra branco de solução de KOH 0,5\% P/V. Para determinar a concentração de bixina nas amostras utilizou-se a equação 1 :

$$
B i \%=\frac{A b \cdot f d \cdot V}{m \cdot E} \times 1,037
$$

Em que:

$A b=$ absorbância adimensional; $f d=$ fator de diluição $(1000 \mathrm{~mL}) ; V=$ volume inicial do extrato $(1000 \mathrm{~mL}) ; E=$ coeficiente específico de extinção (3473), adimensional; $m=$ massa de semente 
(50 g ); 1,037 = fator de conversão para se expressar a concentração em termos de teor de bixina.

\section{RESULTADOS E DISCUSSÃO}

Quando analisada a sensibilidade das cinco espécies bacterianas frente aos três extratos de $B$. orellana $L$. (urucum) a $50 \%$, provenientes de diferentes acessos, independentemente do tipo de extração, tempo de confrontação e presença ou ausência de desinibidores bacterianos, houve diferença significativa entre as bactérias confrontadas (Tabela 1). As bactérias que apresentaram maior sensibilidade foram $E$. faecalis para os acessos Arroio do Meio/RS $(8,3)$ e Eldorado do Sul/RS $(5,5)$ e L. monocytogenes para o acesso Maringá/PR $(6,9)$.

$\mathrm{Na}$ Tabela 2 verifica-se a eficácia da atividade antibacteriana dos três extratos de B. orellana L. (urucum) sobre os inóculos bacterianos em estudo. L. monocytogenes e E. faecalis apresentaram os maiores números arbitrários quanto à sensibilidade em todos os tipos de extração. A maior atividade antibacteriana para essas bactérias foi obtida na forma de extração hidroetanólica, seguida por decocto e infuso que apresentaram atividades quase nulas sobre todas as bactérias testadas.

\section{TABELA 1 - ANÁLISE DA SENSIBILIDADE DE CINCO ESPÉCIES BACTERIANAS DE INTERESSE EM ALIMENTOS FRENTE A SOLUÇÕES CONSERVANTES DE Bixa orellana L., INDEPENDENTE TIPO DE EXTRAÇÃO, TEMPO DE CONFRONTAÇÃO, PRESENÇA OU AUSÊNCIA DE DESINIBIDORES BACTERIANOS}

\section{Arroio do Meio/RS}

Espécies bacterianas

Valores Arbitrários

\begin{tabular}{lc}
\hline Staphylococcus aureus (ATCC 25923) & $4,5^{\mathrm{a}}$ \\
Enterococcus faecalis (ATCC 19433) & $8,3^{\mathrm{b}}$ \\
Listeria monocytogenes (ATCC 19114) & $6,4^{\mathrm{ab}}$ \\
Salmonella Enteritidis (ATCC 11076) & $0,5^{\mathrm{c}}$ \\
Escherichia coli (ATCC 11229) & $0,5^{\mathrm{cd}}$ \\
\hline
\end{tabular}

Eldorado do Sul/RS

Espécies bacterianas

Valores Arbitrários

\begin{tabular}{ll} 
Staphylococcus aureus (ATCC 25923) & $5,4^{\mathrm{a}}$ \\
Enterococcus faecalis (ATCC 19433) & $5,5^{\mathrm{a}}$ \\
Listeria monocytogenes (ATCC 19114) & $3,7^{\mathrm{ab}}$ \\
Salmonella Enteritidis (ATCC 11076 & $1,6^{\mathrm{bc}}$ \\
Escherichia coli (ATCC 11229) & $0,2^{\mathrm{c}}$ \\
\hline
\end{tabular}

Maringá/PR

Espécies bacterianas

Valores Arbitrários

\begin{tabular}{ll}
\hline Staphylococcus aureus (ATCC 25923) & $5,6^{\mathrm{a}}$ \\
Enterococcus faecalis (ATCC 19433) & $5,9^{\mathrm{a}}$ \\
Listeria monocytogenes (ATCC 19114) & $6,9^{\mathrm{a}}$ \\
Salmonella Enteritidis (ATCC 11076 & $4,6^{\mathrm{a}}$ \\
Escherichia coli (ATCC 11229) & $0,6^{\mathrm{b}}$ \\
\hline
\end{tabular}

12 a 1 = valores arbitrários que representam a intensidade da atividade antibacteriana (média de 3 repetições). $0=$ não atividade. Letras minúsculas diferentes sobrescritas na mesma coluna por acesso indicam diferenças significativas entre as espécies bacterianas para a análise de variância (Anova) e teste de Tukey $(p<0,05)$. 
TABELA 2 - ANÁLISE DA RELAÇÃO ENTRE ESPÉCIES BACTERIANAS DE INTERESSE

EM ALIMENTOS E DIFERENTES TIPOS DE EXTRAÇÃO DE Bixa orellana L. (URUCUM), INDEPENDENTE DO TEMPO DE CONFRONTAÇÃO, PRESENÇA OU AUSÊNCIA DE DESINIBIDORES BACTERIANOS E TIPO DE ACESSO

\begin{tabular}{|c|c|c|c|c|c|}
\hline \multirow[b]{2}{*}{ Tipos de Extração } & \multicolumn{5}{|c|}{ Espécies bacterianas } \\
\hline & $\begin{array}{c}\text { Staphylococcus } \\
\text { aureus }\end{array}$ & $\begin{array}{c}\text { Enterococcus } \\
\text { faecalis }\end{array}$ & $\begin{array}{c}\text { Listeria } \\
\text { monocytogenes }\end{array}$ & $\begin{array}{l}\text { Salmonella } \\
\text { Enteritidis }\end{array}$ & $\begin{array}{l}\text { Escherichia } \\
\text { coli }\end{array}$ \\
\hline Hidroetanólica & $4,3^{\mathrm{aA}}$ & $5,2^{\mathrm{aA}}$ & $5,3^{\mathrm{aA}}$ & $2,2^{\mathrm{aB}}$ & $0,3^{\mathrm{ac}}$ \\
\hline Decocto & $0,1^{\mathrm{bA}}$ & $0,1^{\mathrm{bA}}$ & $0,1^{\mathrm{bA}}$ & $0^{\mathrm{bA}}$ & $0^{\mathrm{aA}}$ \\
\hline Infuso & $0,0^{\mathrm{bA}}$ & $0,1^{\mathrm{bA}}$ & $0,1^{\mathrm{bA}}$ & $0^{\mathrm{bA}}$ & $0^{\mathrm{aA}}$ \\
\hline
\end{tabular}

12 a 1 = valores arbitrários que representam a intensidade da atividade antibacteriana (média de 3 repetições). $0=$ não atividade. Letras minúsculas diferentes sobrescritas na mesma coluna indicam diferenças significativas entre os tipos de extração e letras maiúsculas diferentes sobrescritas na mesma linha indicam diferenças significativas entre as espécies bacterianas para a análise de variância (Anova) e teste de Tukey $(p<0,05)$.

Independentemente das demais variáveis manipuladas, as três formas de extração (Tabela 2) apresentaram diferenças significativas entre si $(p<0,05)$. A extração hidroetanólica evidenciou valores superiores aos demais tipos de extração, seguida pelo decocto e infuso. Passos, Carvalho e Wiest (2009), Souza e Wiest (2007) e Girolometto et al. (2009), embora testando outras plantas com a mesma metodologia, também obtiveram resultados superiores para a forma de extração hidroalcoólica e inferiores para os decoctos e infusos. Tais diferenças indicam a perda de componentes como óleos essenciais (mais especificamente o all-E-geranilgeraniol, monoterpenos e sesquiterpenos oxigenados, assim como dos carotenoides bixina e norbixina) presentes na $B$. orellana nas extrações por decocção e infusão em que são utilizadas temperaturas mais elevadas (ebulição).

Analisando diretamente os números absolutos arbitrados, os três maiores valores de sensibilidade antibacteriana foram encontrados, em ordem decrescente, na forma de extração hidroalcoólica atuando sobre L. monocytogenes $(5,3)$, E. faecalis $(5,2)$ e S. aureus $(4,3)$.

Os dois tratamentos com desinibidores/bactericidia (IINAB) e sem desinibidores/ bacteriostasia (IINIB) em relação à espécie bacteriana testada, independentemente do fator tempo de confrontação, apresentaram diferenças significativas (Tabela 3). O tratamento IINIB (bacteriostasia/inibição pela ausência de desinibidores) demonstrou resultado superior ao de IINAB (bactericidia/inativação pela presença de desinibidores) para todas as espécies bacterianas, exceto para S. enteritidis (acessos Arroio do Meio/RS e Eldorado do Sul/RS), E. coli (todos os acessos) e $L$. monocytogenes (acessos Arroio do Meio/RS e Eldorado do Sul/RS). Assim, a ação bacteriostática dos extratos de $B$. orellana foi superior em sua quase totalidade à ação bactericida. Passos et al. (2009), Souza e Wiest (2007), Girolometto et al. (2009) e Carvalho et al. (2005), testando outras plantas e aplicando a mesma metodologia, também obtiveram resultados superiores para IINIB em relação ao IINAB.

A Tabela 3 mostra a presença ou ausência de desinibidores atuando sobre as diferentes bactérias. Os resultados evidenciaram maior atividade bactericida (IINAB, com desinibidor) para S. enteritidis (acesso Maringá/PR), seguida por L. monocytogenes (acessos Arroio do Meio/RS e Eldorado do Sul/RS) e de S. aureus (acesso Maringá/PR). Já a maior atividade bacteriostática (IINIB, sem desinibidor) foi observada para E. faecalis (acesso Eldorado), seguida por L. monocytogenes e E. faecalis (acesso Maringá/PR) e por S. aureus (acessos Maringá/PR e Eldorado do Sul/RS). 
TABELA 3 - ANÁLISE DA PRESENÇA OU AUSÊNCIA DE DESINIBIDORES BACTERIANOS NA ATIVIDADE ANTIBACTERIANA DE EXTRATOS DE Bixa orellana L, INDEPENDENTE DO TEMPO DE CONFRONTAÇÃO, CONSIDERANDO ESPÉCIES BACTERIANAS E EXTRAÇÃO POR HIDROALCOOLATURA

\begin{tabular}{lcccccccccc}
\hline & \multicolumn{3}{c}{ Arroio do Meio/RS } & \multicolumn{3}{c}{ Eldorado do Sul/RS } & \multicolumn{3}{c}{ MaringálPR } \\
\cline { 2 - 10 } Espécie bacteriana & IINIB & IINAB & $p$-value & IINIB & IINAB & $p$-value & IINIB & IINAB & $p$-value \\
\hline Staphylococcus aureus & 4,7 & 0,2 & 0,0028 & 9,3 & 1,5 & 0,0125 & 9,3 & 2 & 0,0102 \\
Enterococcus faecalis & 8,5 & 0,3 & 0,0004 & 10,5 & 0,5 & 0,0058 & 10,3 & 1,5 & 0,0189 \\
Listeria monocytogenes & 6,5 & 2,3 & 0,0989 & 7,3 & 2,3 & 0,0590 & 10,3 & 1,5 & 0,0029 \\
Salmonella Enteritidis & 0,5 & 0,5 & - & 2,3 & 1,0 & 0,0796 & 5,8 & 3,5 & 0,0029 \\
Escherichia coli & 0,5 & 0 & 0,3910 & 0,3 & 0,1 & 0,3910 & 1,0 & 0,3 & 0,2152 \\
\hline
\end{tabular}

12 a 1 = valores arbitrários que representam a intensidade da atividade antibacteriana (média de 3 repetições). $0=$ não atividade. $p$-value $<0,05$ indica diferença significativa entre os valores de IINIB e IINAB pelo teste T, considerando espécies bacterianas e acessos.

Vários autores analisaram a atividade bactericida da planta B. orellana L. (urucum) para as bactérias $S$. aureus e $E$. faecalis, porém mediante outras técnicas de avaliação de sensibilidade antimicrobiana. Gonçalves (2005), Irobi (1996) e Galindo-Cuspinera e Rankin (2005) observaram atividade antibacteriana eficaz frente à S. pyogens, P. mirabilis, B. subtilis, S. aureus e E. faecalis, principalmente para bactérias Gram-positivas.

Os tipos de acesso da planta em estudo, sua ação sobre os diferentes inóculos bacterianos e o teor de bixina presente nas sementes, independentemente do tempo de confrontação, da espécie bacteriana e da presença ou ausência de desinibidores bacterianos na atividade antibacteriana de extratos de $B$. orellana L. (Urucum) são mostrados na Tabela 4. Os resultados revelaram que o extrato hidroetanólico obtido do acesso de Maringá/PR (3,11\% de bixina) foi o mais eficiente, seguido pelo extrato do acesso de Eldorado do Sul/RS (1,33\% de bixina), sendo o de Arroio do Meio/ RS $(1,23 \%)$ o menos sensível. $O$ acesso proveniente de Maringá demonstrou o maior teor de bixina, possivelmente por se tratar de cultivar selecionado submetido à otimização de manejo, enquanto que os demais acessos constituem exemplares subespontâneos, individuais, semi-cultivados (BRAUNBLANQUET, 1979; KENT e COKER, 1992).

\section{TABELA 4 - ANÁLISE DA RELAÇÃO DA ATIVIDADE ANTIBACTERIANA ENTRE OS DIFERENTES ACESSOS DE Bixa orellana L. E O TEOR DE BIXINA PRESENTE NAS SEMENTES, INDEPENDENTE DO TEMPO DE CONFRONTAÇÃO, ESPÉCIE BACTERIANA DE INTERESSE EM ALIMENTOS E DA PRESENÇA OU AUSÊNCIA DE DESINIBIDORES BACTERIANOS}

\begin{tabular}{lcc}
\hline Acesso & Valores Arbitrários & $\begin{array}{c}\text { Teor de bixina nas } \\
\text { sementes (\%) }\end{array}$ \\
\hline Arroio do Meio/RS & $2,4^{\mathrm{a}}$ & $1,23^{\mathrm{a}}$ \\
Eldorado do Sul/RS & $3,5^{\mathrm{b}}$ & $1,33^{\mathrm{b}}$ \\
Maringá/PR & $4,7^{\mathrm{c}}$ & $3,11^{\mathrm{c}}$ \\
\hline
\end{tabular}

12 a 1 = valores arbitrários que representam a intensidade da atividade antibacteriana (média de 3 repetições). $0=$ não atividade. Letras minúsculas diferentes sobrescritas na mesma coluna indicam diferenças significativas entre os acessos para a análise de variância (Anova) e teste de Tukey $(p<0,05)$. 
Quanto às determinações de percentual de bixina dos diferentes acessos estudados, os resultados confirmaram a hipótese inicial de que a relação entre o teor de bixina mostra-se diretamente proporcional à atividade antibacteriana (Tabela 4).

Em síntese, todos os extratos hidroetanólicos de $B$. orellana testados demonstraram capacidade de inibição e/ou inativação seletiva in vitro sobre os cincos inóculos bacterianos de interesse em alimentos estudados. As bactérias mais sensíveis à atividade antibacteriana dos extratos, independente do tipo de extração, foram $E$. faecalis e $L$. monocytogenes, enquanto $E$. coli evidenciou a menor sensibilidade.

\section{CONCLUSÃO}

Nas condições do experimento efetuado concluiu-se que a atividade antibacteriana de extratos de sementes secas de $B$. orellana mostrou-se seletiva, sendo as bactérias Gram-positivas mais sensíveis.

Independente da forma de extração, do acesso e da classificação bacteriana (Gram-positiva ou negativa), a intensidade da atividade de inibição bacteriana/bacteriostasia (IINIB) prevaleceu sobre à intensidade da atividade de inativação bacteriana/bactericidia (IINAB) de diferentes extratos de sementes secas de $B$. orellana a $50 \%$, com exceção de $S$. enteritidis para o extrato do acesso Arroio do Meio.

Diferentes acessos apresentam atividade antibacteriana distintas, provavelmente relacionadas com o solo, o clima, a disponibilidade de fitonutrientes, a genética e a seleção, influenciando os teores de bixina presentes nas sementes.

As formas de extração baseadas no calor (decocto e infuso) podem interferir na eficácia antibacteriana dos extratos devido extração ineficiente, por perda (evaporação) ou mesmo por desnaturação de princípios bioativos.

Os resultados obtidos indicaram a inclusão de L. monocytogenes como micro-organismo alvo de maior número de pesquisas quanto ao uso de antibacterianos naturais frente a esse agente causa.

Os resultados sugerem a continuidade de estudos objetivando a aplicação de diferentes métodos de obtenção de extratos de sementes de $B$. orellana, tanto para serem utilizados como solução conservante ou como condimento, com perspectiva de qualidade, segurança e sensorialidade alimentar.

\section{ABSTRACT \\ "IN VITRO" ANTIBACTERIAL ACTIVITY OF DIFFERENT ACCESSIONS OF ANNATTO (Bixa orellana L.) AND ITS RELATION WITH THE CONTENT OF BIXIN PRESENT IN SEEDS}

In the present study were determined the intensity of bacterial inhibition activity (IINIB/bacteriostasy) and the intensity of bacterial inactivation activity (IINAB/bactericidie) from solutions containing hidroetanolic and hydric (decoction and infusion) extracts of tree accesses from Bixa orellana L. (annatto) from Arroio do Meio (RS- Brazil), Eldorado do Sul (RS - Brazil) and Maringá (PR - Brazil), on standardized inocula of Salmonella enteritidis (ATCC 11076), Escherichia coli (ATCC 11229), Staphylococcus aureus (ATCC 25923), Enterococcus faecalis (ATCC 19433) and Listeria monocytogenes (ATCC 19114). In parallel, the content of bixin present in the seeds was also determined. The forms of hydric extraction presented low inhibition and/or inactivation activity of the bacterial inocula. Hidroetanolic extract form on the other hand showed selective antibacterial activity and significantly pronounced inhibition/inactivation against the five bacteria tested. Independent of the extraction form, E. faecalis and L. monocytogenes were the more sensitive agents to the antibacterial activity. E. coli had the lowest sensitivity to all forms of extraction. The bixin contents were significantly different among the three accesses and, consequently, antibacterial activity was directly proportional to these contents.

KEY-WORDS: Bixa orellana; ANTIBACTERIAL ACTIVITY; BACTERIAL INHIBITION; BACTERIAL INACTIVATION; BIXIN. 


\section{REFERÊNCIAS}

1 AGNER, A.R. et al. Absence of carcinogenic and anticarcinogenic effects of annatto in the rat liver medium-term assay. Food and Chemical Toxicology, v.42, n.10, p.1687-93, 2004.

2 AVANCINI, C. et al. Antimicrobial activity of plants used in the prevention and Control of bovine Mastitis in Southern Brazil. Latin American Journal of Pharmacy, v. 27, n.6, p.894-9, 2008.

3 AVANCINI, C.A.M.; WIEST, J.M. Atividade desinfetante do decocto de Hypericum caprifoliatum Cham. e Schlecht. Guttiferae (escadinha, sinapismo) frente a diferentes doses infectantes de Staphylococcus aureus (agente infeccioso em mastite bovina). Revista Brasileira de Plantas Medicinais, v.10, n.1, p.64-9, 2008.

4 BRAGA, F. G. et al. Antileishmanial and antifungal activity of plants used in traditional medicine in Brazil. Journal of Ethnopharmacology, v.111, n.2, p.267-71, 2007.

5 BRASIL. Ministério da Saúde. Agência Nacional de Vigilância Sanitária. Portaria n540-SVS/MS, de 27 de outubro de 1997. Regulamento técnico para aditivos alimentares. Disponível em: <http://e-legis.anvisa.gov.br>. Acesso em: 10 ago. 2008.

6 BRAUN-BLANQUET, J. Fitossociologia: bases para el estudio de las comunidades vegetais. Madrid: M. Blume Ediciones, 1979. $820 \mathrm{p}$.

7 CARVALHO, H.H.C. et. al. Atividade antibacteriana em plantas com indicativo etnográfico condimentar em Porto Alegre, RS/Brasil. Revista Brasileira de Plantas Medicinais, v. 7, n.3, p.25-32, 2005.

8 CARVALHO, H.H.; WIEST, J.M.; CRUZ, F.T. Atividade antibacteriana in vitro de pimentas e pimentões (Capsicum sp.) sobre quatro bactérias toxinfectivas alimentares. Revista Brasileira de Plantas Medicinais, v.12, n.1, p.8-12, 2010.

9 CAVALLI-SFORZA, L. Biometrie: grundzüge biologisch-medizinische statistic (Biometria: fundamentos de estatística viológica-médica). Stuttgart: Gustav Fisher, 1974. p.201-4.

10 DOWNHAM, A.; COLLINS, P. Colouring our foods in the last and next millennium. International Journal of Food Science and Technology, v.35, n.1, p.5-22, 2000.

11 DVG. Deutsche Veterinärmedizinische Gesellschaft. Richtlinien zur prüfung chemischer desinfektionsmittel für die veterinärmedizin. In: SCHLIESSER, T.H.; STRAUCH, D. Desinfektion in tierhaltung, fleisch- und milchwirtschaft. Stuttgar, 1981. 455 p.

12 FARMACOPÉIA brasileira. 3. ed. São Paulo: Organização Andrei Editora, 1987. 1218 p.

13 FLEISCHER, T.C. et al. Antimicrobial activity of the leaves and seeds of Bixa orellana. Fitoterapia, v.74, n.1-2, p.136148, 2003.

14 GALINDO-CUSPINERA, V.; RANKIN, S.A. Bioautography and chemical characterization of antimicrobial compound(s) in commercial water-soluble annatto extracts. Journal Agriculture Food Chemistry, v.53, n.7, p.2524-9, 2005.

15 GIROLOMETTO, G. et al. Avaliação da atividade antibacteriana de extratos de erva mate (Ilex paraguarienses A. St. Hill.). Revista Brasileira de Plantas Medicinais, v.11, n.1, p.49-55, 2009.

16 GONÇALVES, A.L. et al. Estudo comparativo da atividade antimicrobiana de extratos de algumas árvores nativas. Arquivos do Instituto Biológico, v.72, n.3, p.353-8, 2005.

$17 \mathrm{IROBI}, \mathrm{O} . \mathrm{N}$. et al. Antimicrobial activity of annatto (Bixa orellana) extract. International Journal of Pharmacognosy, v.34, n.2, p.87-90, 1996.

18 ITF. Índice Terapêutico Fitoterápico. Ervas medicinais. Petrópolis: EPUB, 2008. 328 p.

19 KENT, M.; COKER, P. Vegetation description and analysis: a practical approach. London: Blackwell, 1992. 544 p.

20 LIMA, A. Remédios da floresta. Como utilizar? Enfermagem Atual, v.8, n.46, p.34-40, 2008.

21 LIVERMORE, D.M. Introduction: the challenge of multiresistance. International Journal of Antimicrobial Agents, v.29, n.3, p.S1-7, 2007.

22 LORENZI, H.; MATOS, F.J.A. Plantas medicinais no Brasil: nativas e exóticas. 2. ed. Nova Odessa: Instituto Plantarum, 2008. $576 \mathrm{p}$.

$23 \mathrm{MAU}$, J.L. et al. Antimicrobial effect of extracts from Chinese chive, cinnamon, and coni fructus. Journal of Agricultural and Food Chemistry, v.49, n.1, p.183-8, 2001.

24 MING, L.C. Coleta de plantas medicinais. In: DI STASI, L.C. Plantas medicinais arte e ciência: um guia de estudo interdisciplinar. São Paulo: Editora da UNESP, 1996. p. 69-86. 
25 NALIMOVA, M.S. et al. Efecto in vitro de extractos de plantas sobre especies bacterianas del gênero Xantomonas. Fitosanidad, v.9, n.3, p.49-51, 2005.

26 NASCIMENTO, G.G.F et al. Antibacterial activity of plant extracts and phytochemicals on antibiotic-resistant bactéria. Brazilian Journal of Microbiology, v.31, n.2, p.247-56, 2000.

27 PASSOS, M.G. et al. Inibição e inativação bacterianas "in vitro" de diferentes formas de extração de Ocimum gratissimum L. (alfavacão, alfavaca, alfavaca-cravo) - Labiatae (Lamiaceae), frente a bactérias de interesse em alimentos. Revista Brasileira de Plantas Medicinais, v.11, n.1, p.71-8, 2009.

28 ROJAS, J.J. et. al. Screening for antimicrobial activity of ten medicinal plants used in Colombian folkloric medicine: possible alternative in the treatment of non-nosocomial infections. BMC Complementary and Alternative Medicines, v.6, n.1, p.2-12, 2006.

29 ROMEIRO, R.S. Técnica de microgota para contagem de células bacterianas viáveis em uma suspensão. Bactérias fitopatogênicas. Disponível em: <http://www.ufv.br/dfp/bac/uni9.pdf>. Acesso em: 23 mar. 2008.

30 SISVAR 5.0. Softwares downloads. Disponível em: <http://www.dex.ufla.br/ danielff/softwares.htm>. Acesso em: 28 out. 2009 .

31 SOUZA, A.A.; WIEST, J.M. Atividade antibacteriana de Aloysia gratissima (Gill et Hook) Tronc. (garupá, erva-santa) usada na medicina tradicional no Rio Grande do Sul - Brasil. Revista Brasileira de Plantas Medicinais, v.9, n.3, p.23-29, 2007.

32 VERÍSSIMO, S.A. et al. Aproveitamento do corante natural (Bixa orellana) no tingimento de fibra celulósica. Tecnologia \& Ciência Agropecuária, v.2, n.1, p.35-39, 2008.

33 VIUDA-MARTOS, M. et al. Antibacterial activity of different essential oils obtained from spices widely used in Mediterranean diet. International Journal of Food Science and Technology, v.43, n.3, p.526-531, 2008.

34 WIEST, J.M. et al. Inibição e inativação "in vitro" de Salmonella spp. com extratos de plantas com indicativo etnográfico medicinal ou condimentar. Arquivo Brasileiro de Medicina Veterinária e Zootecnia, v.61, n.1, p.119-127, 2009.

35 WU, V.C.H. A review of microbial injury and recovery methods in food. Food Microbiology, v.25, n.6, p. 735-44, 2008. 